\title{
Properties of Oxidized Starch Prepared by Hydrogen Peroxide, Chlorine Dioxide and Sodium Hypochlorite
}

\author{
Bing HAN* \\ College of Food Science and Engineering, Harbin University of Commerce, Harbin, \\ Heilongjiang, 150076, P.R. China \\ hb790118@163.com \\ ${ }^{*}$ Corresponding author
}

Keywords: Oxidized Starch, Hydrogen Peroxide, Chlorine Dioxide, Sodium Hypochlorite.

\begin{abstract}
Chlorine peroxide, Sodium hypochlorite and hydrogen peroxide were chosen as oxidant to prepare potato oxidized starch, and the properties of oxidized starch were determined. The results showed that carbonyl content of oxidized starch prepared by $\mathrm{H}_{2} \mathrm{O}_{2}$ is $0.329 \%$, much higher than other oxidized starch and potato starch. Gelatinized viscosity of oxidized starch prepared by $\mathrm{ClO}_{2}$ is $15.69 \mathrm{~Pa}$. s, significantly increased. All these starch were characterized by Fourier Thansform Infrared Spectroscopy (FT-IR). Different oxidized position and oxidized extent due to different oxidant were observed.
\end{abstract}

\section{Introduction}

Starch is a renewable and biodegradable macromolecule. It has attracted great interest and as an important raw material for low cost and abundant resource. However, the hydrophilic $\mathrm{OH}$ groups of the unmodified starch molecule tend to constitute intermolecular and intramolecular hydrogen bonds, limiting the application of the material for certain applications. Some oxidizing agents with different redox potentials have been tested to modify starch by introducing $\mathrm{COOH}$ and $\mathrm{CHO}$ groups [1]. At a suitable temperature and $\mathrm{pH}$ value, starch can be oxidized by periodate, chromic acid, permanganate, nitrogen dioxide, and sodium hypochlorite [2]. During oxidation, starch loses its original crystallization, and the hydroxyl groups in the glucose ring are partially oxidized to aldehyde or ketone groups, which weaken the hydrogen bonds between the starch chains [3].

Though the oxidized starch prepared by $\mathrm{H}_{2} \mathrm{O}_{2}$ has already been characterized [4], there is no report on properties of oxidized starch prepared by different oxidant. In previous studies, we found that when the hydroxyl groups in glucose ring of starch were oxidized to aldehyde groups, both the mechanical properties and hydrophobicity of thermoplastic starch were improved [5]. In this study, properties of oxidized starch with carboxyl of same content by Hydrogen Peroxide, Chlorine Dioxide and Sodium Hypochlorite were evaluated, and some properties of them were investigated.

\section{Materials and Methods}

\section{Materials}

Potato starch (10.8\% moisture) was obtained from Jilin Qishen Food Company (technical grade, Changchun, Jilin, China). Hydroxyl peroxide $\left(\mathrm{H}_{2} \mathrm{O}_{2}, 30 \%\right)$, Sodium hypochlorite, and Chlorine dioxide were purchased from Kelong Chemical Reagent. 
All other chemicals and solvents used were of analytical grade $(99.5 \%)$ and used without purification.

\section{Preparation of Oxidized Starches}

Oxidized starch prepared by hydroxyl peroxide, chlorine dioxide and sodium hypochlorite were produced according to the following procedures respectively [6-8]. $50 \mathrm{~g}$ potato starch and $250 \mathrm{~mL}$ distilled water were mixed and heated at $80^{\circ} \mathrm{C}$ for 30 min with mild stirring. 1) $25 \mathrm{~mL} \mathrm{H} 2 \mathrm{O} 2(30 \%)$ was added in the mixture after the temperature dropped to $40^{\circ} \mathrm{C}$ for $4 \mathrm{~h}$. 2) Potato starch was oxidized with concentration of sodium hypochlorite at $6 \%$ and $\mathrm{pH}$ at 7.0 for $3 \mathrm{~h}$. 3) Starch slurry contain $0.15 \%$ chlorine dioxide and activator was stirred at $35^{\circ} \mathrm{C}$ for $2.5 \mathrm{~h}$. The slurry was separated by slow-speed centrifugation and the precipitated product was washed with five $200 \mathrm{~mL}$ portions of distilled water before drying for $24 \mathrm{~h}$ at $50^{\circ} \mathrm{C}$ in a vacuum oven.

\section{Determination of Carboxyl Content}

The carboxyl content of oxidized starch was determined according to the modified procedure [9]. About $2 \mathrm{~g}$ of oxidized starch sample was mixed with $25 \mathrm{~mL}$ of $0.1 \mathrm{~mol} / \mathrm{L}$ $\mathrm{HCl}$, and the slurry was stirred continually for $30 \mathrm{~min}$ with a magnetic stirrer. Subsequently, the slurry was vacuum-filtered through a medium porosity fritted glass funnel and washed with distilled water until without chlorine ion. The starch cake was then carefully transferred into a $150 \mathrm{~mL}$ beaker. After mixed with $100 \mathrm{~mL}$ water, the starch slurry was heated to $100^{\circ} \mathrm{C}$ with continuous stirring for 3-5 min. The hot starch dispersion was then adjusted to $300 \mathrm{~mL}$ with distilled water, and then standard $\mathrm{NaOH}$ solution was dripped into the sample solution slowly, and the titration end point was judgedby potentiometer ( $\mathrm{pH} 8.3$ ). A blank test was performed with unmodified starch. The carboxyl content was calculated as follows:

$-\mathrm{COOH}(\%)=\left(\mathrm{V}_{1} / \mathrm{m}_{1}-\mathrm{V}_{0} / \mathrm{m}_{0}\right) \times \mathrm{c} \times 0.045 \times 100$

$\mathrm{V}_{1}$ and $\mathrm{V}_{0}$ are the volumes of the consumed standard $\mathrm{NaOH}$ solution $(\mathrm{mL})$ for the titration of samples and blank, $\mathrm{m}_{1}$ and $\mathrm{m}_{0}$ are the masses of the sample and unmodified starch, and $\mathrm{c}$ is the concentration of $\mathrm{NaOH}(\mathrm{mol} / \mathrm{L})$, respectively.

\section{Determination of Carbonyl Content}

Carbonyl content was performed as described previously [10]. $5 \mathrm{~g}$ of oxidized starch was dispersed in $100 \mathrm{~mL}$ of distilled water, and the suspension was gelatinized by heating in a boiling water bath and then cooled to $40^{\circ} \mathrm{C} .60 \mathrm{~mL}$ of hydroxylamine reagent $(25 \mathrm{~g}$ hydroxylamine hydrochloride dissolved in $100 \mathrm{~mL}$ of $0.5 \mathrm{~mol} / \mathrm{L} \mathrm{NaOH}$. Subsequently, the solution was made up to $500 \mathrm{~mL}$ with distilled water) was added after adjusting $\mathrm{pH}$ to 3.2. The sample was covered with aluminum foil and placed in a water bath at $40^{\circ} \mathrm{C}$ for $4 \mathrm{~h}$. The excess hydroxylamine was determined by rapid titration of the reaction mixture to $\mathrm{pH} 3.2$, with $0.1 \mathrm{~mol} / \mathrm{L} \mathrm{HCl}$. Blank test was performed with unmodified starch. Carbonyl content was calculated as follows:

$$
-\mathrm{C}=\mathrm{O}(\%)=(\mathrm{V} 1-\mathrm{V} 0) \times \mathrm{c} \times 0.028 \times 100 \div \mathrm{m}
$$

$\mathrm{V}_{1}$ and $\mathrm{V}_{0}$ are the volumes of the consumed $\mathrm{HCl}$ standard aqueous solution $(\mathrm{mL})$ for the titration of sample and blank, $\mathrm{m}$ is the mass of the sample, and $\mathrm{c}$ is the concentration of $\mathrm{HCl}(\mathrm{mol} / \mathrm{L})$, respectively. The apparent viscosity of the cooked samples $(6 \%)$ was measured by using coaxial rotary viscometer, with a rate of shear of 2000 or $350 \mathrm{~s}^{-1}$ at $40^{\circ} \mathrm{C}$. The residual copper was estimated by the atomic adsorption spectrometry. 


\section{Determination of V iscosity}

The viscosity [pa. s] of the oxidized starch was determined with an viscometer at 25.0 $\pm 0.1^{\circ} \mathrm{C}$ in water at a gelatinized sample concentration of about $50 \mathrm{mg} / \mathrm{mL}$.

\section{Measure ment of Clarity and Retrogradation}

The $0.01 \mathrm{~g} / \mathrm{mL}$ water solution of oxidized starch was gelatinized by heating in boiling water and cooled to room temperature. The light transmittance was measured in a spectrophotometer at $650 \mathrm{~nm}$, a control tube contain distilled water was prepared in parallel to each test sample. After deposited for $24 \mathrm{~h}$, light transmittance was measured again. Retrogradation obtained by the difference.

\section{FT-IR Spectroscopy}

The IR spectra were obtained from samples in $\mathrm{KBr}$ pellets using a 170SX FT-IR spectrophotometer (Nicolet, Madison, WI, USA).

\section{Results and Discussions}

\section{Characteristics of Oxidezed Starch}

The carboxyl content of oxidized starches prepared from potato starch was all qualified to about $0.2 \%$. After dehydrated to powder, essential characteristics such as carbonyl content, viscosity, clarity and retrogradation were investigated. Table 1 shows the Carbonyl content of gelatinized starch oxidized with different oxidant. Bidzinska et al found that the reation of oxidant with gelatinized starch did not go to completeness [11]. When hydrogen peroxide chosen as oxidant, significant increase in the carbonyl content of oxidized starch to $0.329 \%$. In contrast, when oxidant shifted to sodium hypochlorite, viscosity of oxidized starch maximized to $15.69 \mathrm{~Pa}$. s. At the same time, no matter what kinds of oxidant was chosen, only an insignificant increase in the clarity and retrogradation were found. This indicated that oxidized starch prepared by different oxidant shown different characteristics.

Table 1. Carbonyl content, viscosity, clarity and retrogradation of oxidized starch

\begin{tabular}{ccccc}
\hline & Potato starch & $\begin{array}{c}\text { Oxidized starch } \\
\text { prepared by } \mathrm{H}_{2} \mathrm{O}_{2}\end{array}$ & $\begin{array}{c}\text { Oxidized starch } \\
\text { prepared by } \mathrm{ClO}_{2}\end{array}$ & $\begin{array}{c}\text { Oxidized starch } \\
\text { prepared by } \mathrm{NaClO}\end{array}$ \\
\hline Carboxyl content (\%) & 0 & 0.20 & 0.20 & 0.20 \\
Carbonyl content (\%) & 0 & 0.329 & 0.009 & 0.045 \\
Viscosity (Pa.s) & 5.255 & 0.11 & 0.074 & 0.692 \\
Clarity & 0.4041 & 0.704 & 0.534 & 0.316 \\
Retrogradation & 0.2582 & 0.252 & 0.431 & 0.69 \\
\hline
\end{tabular}

\section{FT-IR Analysis}

The FT-IR spectra of oxidized starch prepared by different oxidant are shown in Fig. 1. The spectra show an intense band at $1637 \mathrm{~cm}-1$, which was assigned to deformation vibrations of water molecules absorbed by starch [12]. The broad band at $1735 \mathrm{~cm}-1$ is characteristic of $\mathrm{C}=\mathrm{O}$ groups (stretching vibration), produced by oxidation of 
hydroxyl groups to aldehyde and carboxyl groups [13]. FT-IR spectra of oxidized starch prepared with $\mathrm{H} 2 \mathrm{O} 2$ (Figure 1, Curve (a)) exhibited a higher intensity of this absorption peak than other starches (curve (b, c, d)) correlating with its higher carbonyl content as measured by titration (see Table. 1). The band at $2927 \mathrm{~cm}-1$ was attributed to $\mathrm{CH} 2-$ asymmetric stretching vibration. The absorptions at $1460 \mathrm{~cm}-1$ and $1300 \mathrm{~cm}-1$ may be attributed to the $\mathrm{C}-\mathrm{H}$ bending vibration $[14,15]$.

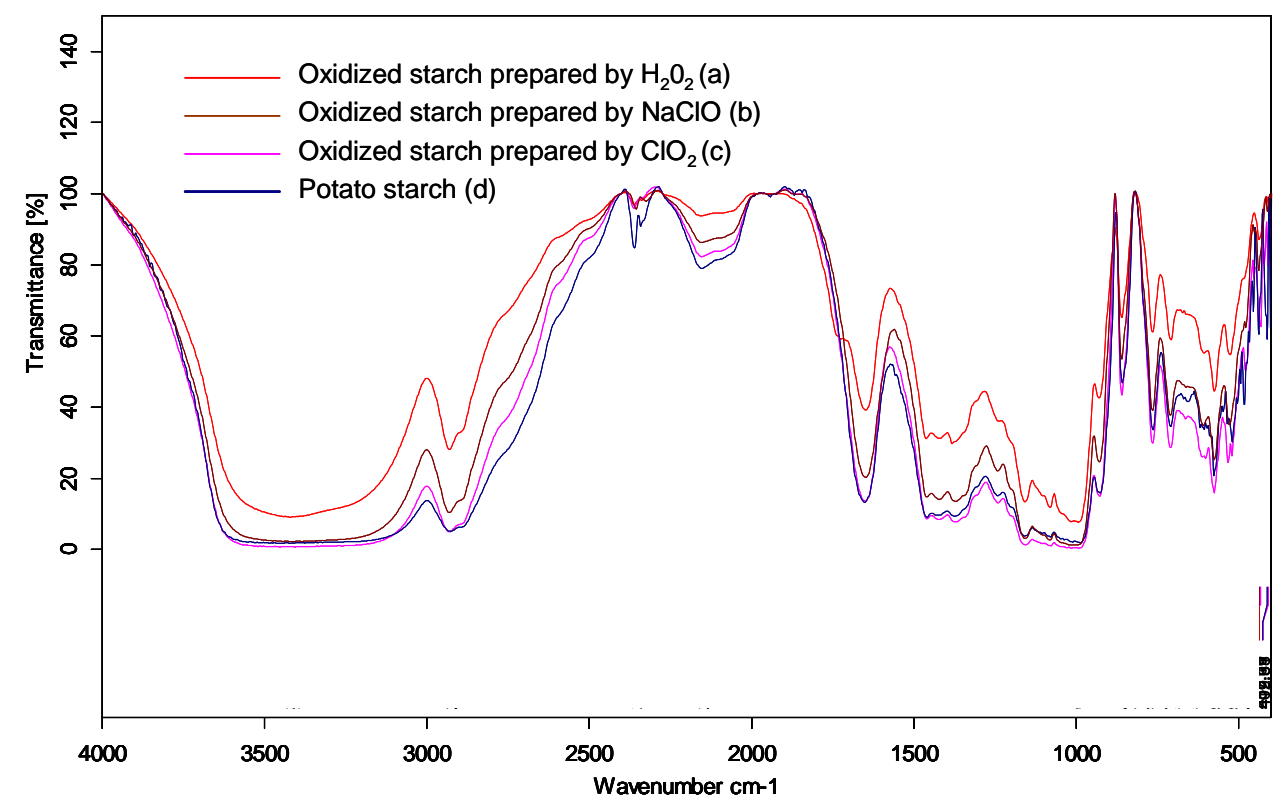

Figure 1 The FT-IR spectra of oxidized starch prepared by different oxidant

\section{Acknowledge ment}

The project was supported by the Research Foundation granted by Education of Heilongiang Province (11551100). This work is supported by Harbin University of Commerce, College of Food Engineering.

\section{References}

[1] P. L. Bragd, A. C. Besemer, H. van Bekkum. Bromide-free TEMPO-mediated oxidation of primary alcohol groups in starch and methyl $\alpha$-D-glucopyranoside. Carbohydr Research. 2000, 328, 355-363.

[2] D. S. Kuakpetoon, Y. J. Wang. Characterization of different starches oxidized by hypochlorite. Starch, 2001, 53, 211-218.

[3] Wang. N., Yu. J. G., Ma. X. F. Preparation and characterization of thermoplastic starch/ PLA blends by one-step reactive extrusion. Polymer international, 2007, 56, 1440-1447.

[4] Hui T. Chan, Rajeev Bhat, Alias A. Karim, Physicochemical and functional properties of Ozone-Oxidized Starch. Journal of agricultrure and Food Chemistry, 2009, 57, 5965-5970

[5] S. D. Zhang, Y. R. Zhang, J. Zhu, X. et al., Modified corn starches with improved comprehensive properties for preparing thermoplastics. Starch, 2007, 59, 258-268. 
[6] Yanxiao Chen, Gongying Wang. Synthesis of Crosslinked Oxidized Starch and Its Adsorption Behavior for Calcium Ion. Journal of Applied Polymer Science, 2006 102(2), 1539-1546.

[7] Yu Rongzhang, Shui Dongzhang, Xiu Liwang et al., Effect of carbonyl content on the properties of the thermoplastic oxidized starch. Carbohydrate polymers, 2009, 78, 157-161.

[8] Shui Dongzhang, Yu Rongzhang, Xiu Liwang, et al., High Carbonyl Content Oxidized Starch Prepared by Hydrogen Peroxide and Its Thermoplastic Application. Starch. 2009, 61, 646-655.

[9] Hualin Wang, Wenjuan Wang, Suwei Jiang et al., Poly (vinyl alcohol) / Oxidized Starch Fibres via Electrospinning Technique: Fabrication and Characterization. Iranian polymer Journal, 2011, 20(7): 551-558

[10] Hui-Tin Chan, Chiu Peng Leh, Rajeev Bhat, et al., Molecular structure, rheological thermal characteristics of ozone-oxidized starch, Food Chemistry, 2011, 126, 1019-1024

[11] Wing, R. E.; Wilett, J. L. Ind Crop Prod 1997, 7, 45.

[12] E Bidzinska, K. Dyrek, T. Fortuna, et al., EPR studies of thermally treated oxidized corn starch. Starch, 2004, 56, 461-468.

[13] S. D. Zhang, Y. R. Zhang, J. Zhu, et al., Modified corn starches with improved comprehensive properties for preparing thermoplastics. Starch. 2007, 59, 258-268.

[14] D. K. Kweon, J. K. Choi, E. K. Kim, et al., Adsorption of divalent metal ions by succinylated and oxidized corn starches. Carbohydr. Polym. 2001, 46, 171-177.

[15] A. Para, Complexation of metal ions with dioxime of dialdehyde starch. Carbohydr. Polym. 2004, 57, 277-283.

[16] J. M. Fang, P. A. Fowler, J. Tomkinson, C. A. S. Hill, The preparation and characterization of a series of chemically modified potato starches. Carbohydr. Polym. $2002,47,245-252$. 